\title{
O uso do HGPE como recurso partidário em eleições proporcionais no Brasil: um instrumento de análise de conteúdo
}

\author{
ב \\ Emerson Urizzi Cervi \\ Departamento de Ciências Sociais \\ Universidade Federal do Paraná \\ $\mathrm{e}$ \\ Departamento de Comunicação \\ Universidade Estadual de Ponta Grossa
}

\begin{abstract}
Resumo: Este artigo apresenta uma tipologia para análise quantitativa de conteúdo do Horário Gratuito de Propaganda Eleitoral (HGPE) de candidatos em disputas proporcionais. Poucos trabalhos abordam descritivamente o conteúdo apresentado pelos candidatos em eleições para vereador e deputado no Brasil e para a análise de conteúdo em disputas para deputado federal no Paraná, em 2006, são propostos três conjuntos de variáveis: indexadoras, elementos semânticos e simbólicos.
\end{abstract}

Palavras-chave: Brasil, eleições proporcionais, HGPE, imagem pública

\begin{abstract}
The article presents a typology for quantitative analysis of mídia content, specifficaly, the Horário Gratuito de Propaganda Eleitoral (HGPE)_ of proportional election`s candidates. There are few studies regarding the content displayed by candidates in local, state and national legislative elections in Brazil, and the content analysis of HGPE for federal deputies in the state of Paraná in 2006 proposes the use of three sets of variables: indexing, semantic and symbolic elements.
\end{abstract}

Keywords: Brazil, proportional campaigns, electoral advertising, public image 


\section{Introdução $^{1}$}

Em disputas eleitorais proporcionais em que o número total de candidatos é muito maior que o número de vagas em disputa, como no caso brasileiro, os concorrentes por partido podem chegar ao dobro das vagas, e as organizações partidárias apresentam dificuldades em conseguir distribuir "recursos de campanha" a todos os participantes. Segundo a legislação eleitoral no Brasil, em campanhas proporcionais cada partido não coligado pode apresentar até uma vez e meia o número de vagas em disputa por distrito eleitoral. No caso de coligações partidárias, o número total de candidatos na coligação pode ser de até duas vezes o número de vagas. Por exemplo, no caso do Estado de São Paulo, que possui 70 vagas na Câmara dos Deputados, um partido que queira disputar a eleição de forma "solteira", ou seja, sem coligação formal, pode ter até 105 candidatos a deputado federal. Caso participe coligado com outros partidos, o número total de concorrentes na coligação passa a ser de 140. Mesmo nas unidades da federação com menor representação no Congresso, tal como Roraima, que conta apenas com 8 vagas na Câmara, o número de concorrentes torna-se expressivo. Se considerarmos uma média de 15 partidos apresentando candidatos a deputado federal, com até 16 concorrentes cada um, pode-se chegar até a 120 pessoas diretamente na disputa.

Ao final, o número de concorrentes a cargos proporcionais torna-se bastante grande. Nas eleições de 2010 foram registrados no Tribunal Superior Eleitoral (TSE) 4878 candidaturas a deputado federal por partidos políticos de todos os Estados brasileiros. Isso representa uma concorrência de 9,5 candidatos por vaga na Câmara dos Deputados, considerando o País como um todo e não levando em conta as diferenças de tamanho dos distritos eleitorais. Esse grande número de postulantes às cadeiras legislativas requer um tipo de organização específica dos partidos, seja porque normalmente eles dão mais atenção para as eleições majoritárias, seja porque os recursos financeiros partidários são limitados.

No Brasil, mesmo nas eleições majoritárias, apenas cerca de $20 \%$ do total de despesas declaradas pelos candidatos têm origem nos fundos partidários (CERVI, 2009). A maior parte é de doações externas, seja de pessoas físicas ou de jurídicas. A baixa capacidade financeira dos partidos gera um desequilíbrio entre candidaturas às eleições proporcionais com aporte privado de recursos e aquelas que não têm acesso às fontes de financiamento tradicionais. Uma das poucas

\footnotetext{
${ }^{1}$ A proposta de variáveis para coleta de dados apresentada aqui foi testada preliminarmente nas eleições para deputado federal do Paraná em 2006 por pesquisadores dos grupos de pesquisa em Comunicação Política e Opinião Pública, da UFPR (Universidade Federal do Paraná); e de Mídia, Política e Atores Sociais, da UEPG (Universidade Estadual de Ponta Grossa). Agradeço às pesquisadoras de Iniciação Científica Camila Montagner Fama e Ana Claudia Massambani, responsáveis pela coleta dos dados, e a Leonardo Barretta pela leitura cuidadosa e revisão das tabelas.
} 
formas que as estruturas partidárias têm para parcialmente corrigir esse desequilíbrio é a distribuição igualitária do tempo disponível no Horário Gratuito de Propaganda Eleitoral (HGPE) para as disputas proporcionais. O tempo de exposição na televisão é considerado um recurso de campanha importante por muitos autores, inclusive em países onde não há espaço regulamentado para os partidos (MANCINI e SWANSON, 1996; GIBSON e RÖMMELE, 2001; ALBUQUERQUE, 2005; RÖMMELE, 2006). Assim, analisar a ocupação do tempo de HGPE pelos candidatos é relevante para compreender a distribuição dos recursos políticos sob responsabilidade dos partidos.

O fato é que as candidaturas já começam o processo eleitoral em desigualdade de condições. $E$ isso não se dá apenas em relação às fontes e montantes de recursos financeiros, pois as próprias características de origem dos candidatos impõem diferenças. Por exemplo, enquanto existem candidatos em disputa pela primeira vez ou sem ocupar cargo no Estado, existem aqueles que estão concorrendo à reeleição, dotados de mais voz e poder decisório nas estruturas partidárias. Há também os que ocupam cargos nomeados no aparato estatal ou os que fazem parte da estrutura partidária propriamente dita. A questão que se coloca aqui é se a partir da análise do HGPE é possível identificar possíveis desequilíbrios na distribuição do recurso partidário "tempo em rádio e televisão" entre os candidatos. E, se o desequilíbrio ocorrer, que tipo de concorrente é beneficiado ou não pelas decisões de ocupação do tempo destinado ao partido para as campanhas nos meios eletrônicos?

Para tanto, trata-se de identificar determinados espaços nobres no HGPE em termos quantitativos e qualitativos e, em seguida, relacionar com as aparições dos candidatos neles. Não se pretende, aqui, indicar algum tipo de relação causal entre mais espaço no HGPE e maior número de votos, o que seria um risco dadas as condições tão diversas de disputa eleitoral no Brasil. Análises de distribuição espacial de voto mostram que há candidatos que se elegem com votos dispersos e para esses o tempo em televisão é relevante. Mas, há outros que conseguem votos muito concentrados em determinada região geográfica do distrito eleitoral e, nesses casos, o impacto do HGPE é minimizado pela necessidade de um corpo a corpo com os eleitores (MAINWARING, 1995; SAMUELS, 1997). O que se pretende é identificar os resultados das escolhas internas dos partidos na distribuição de recursos de campanha, no caso, tempo e posição no HGPE, para os seus candidatos. Trata-se de uma análise de conteúdo do horário eleitoral para tentar mostrar se os concorrentes têm acesso igualitário a esse "bem escasso" ou se existe um padrão de favorecimento a determinado tipo de candidatura.

Também busca-se identificar o uso que os candidatos fazem desse espaço para criar e difundir uma imagem pública. Em democracias universais de sociedades complexas como a nossa, a intermediação dos meios de comunicação 
nas relações de representação política torna-se indispensável. É a partir da mídia que a elite política consegue apresentar-se às massas eleitorais, criando um discurso e montando uma imagem que pretende ser a mais adequada para os eleitores. No caso de disputas majoritárias, quando existe apenas um candidato por partido, a imagem pública do concorrente torna-se a imagem do seu partido. Nos casos das proporcionais, por sua vez, onde existem dezenas ou centenas de concorrentes pelo mesmo partido, há um potencial maior de autonomia e fragmentação dos discursos entre os candidatos (WATTENBERG, 1991; SCHMIDT, 1996; CAIN \& FIORINA, 1987; LAWSON \& MERKL, 1988). Cada concorrente pode procurar uma característica específica para ser explorada no HGPE, em detrimento das propostas mais gerais de identificação da estrutura partidária a que está vinculado. O horário eleitoral é o espaço privilegiado para identificar a independência na formação das imagens públicas dos concorrentes aos cargos proporcionais.

São os meios de comunicação de massa os espaços próprios, por natureza, para a formação de imagens públicas em sociedades complexas (NEGRINE \& LILLEKER, 2002). A partir deles são difundidas não apenas mensagens temáticas, relacionando candidatos a determinados assuntos, tal como um delegado de polícia com o tema do combate à violência ou uma líder comunitária com as questões próprias da sua região. Também é possível criar imagens públicas estereotipadas, tais como a de representante de determinada cultura étnica quando o concorrente participa do HGPE vestido com indumentária típica. Ou, quando adota o discurso da moralidade, apelando para sua história de vida pregressa. Essa imagem pode ser mais próxima de um padrão geral identificado com o partido político ou pode ser mais independente em relação à estrutura partidária. O instrumento de coleta de informações apresentado a seguir é dividido em dois momentos para permitir a captura de informações para os dois tipos de análise: partidária e individual.

Desde o final dos anos 1980, no Brasil, o horário eleitoral em rádio e tevê tem chamado a atenção de pesquisadores da área, reconhecendo a centralidade da mídia de massa para as relações de representação política contemporânea. Tendo começado com a análise em disputas majoritárias, o HGPE tornou-se uma referência quase permanente na identificação de padrões de campanhas políticas em nível local, regional ou nacional. Essa foi uma forma encontrada nas sociedades complexas para viabilizar a difusão de imagens e discursos públicos, democratizando o acesso à informação. Porém, a conseqüência natural é uma transformação no modo como o debate político é produzido, que se torna mais lúdico e permeado por elementos constituintes do discurso midiático, tais como a encenação da realidade e exploração de estereótipos. Nesse cenário, a televisão surge de maneira singular em função de sua capacidade de massificar as mensagens e torna-se fundamental para as ações de políticos que desejam sucesso 
em campanhas eleitorais (OLIVEIRA, 2008). São os meios de comunicação eletrônica que permitem a maior visibilidade de candidatos frente aos eleitores, com relativa interação entre eles. É evidente que o advento da internet ampliou em muito a interação até então limitada entre representante e representado pela televisão e outros meios que não permitem uma interação mais contínua. Porém, de maneira geral a mídia tornou-se o principal instrumento de contato entre a elite política e os cidadãos comuns (MIGUEL, 2004, p.8). Nesse sentido, o HGPE em rádio e televisão desempenha um papel central nas definições de estratégias de campanha dos partidos e dos próprios candidatos.

Por considerarem o HGPE um dos dispositivos mais relevantes da disputa eleitoral, os partidos também pautam suas alianças considerando o tempo disponível na televisão e a forma como ele será distribuído entre os candidatos. Por esse motivo, não se deve esperar uma distribuição equitativa entre todos os concorrentes como uma conseqüência natural da organização. Pelo contrário, por ser moeda de troca, pode entrar no cômputo dos acordos entre cúpulas partidárias. Um segundo motivo para a distorção na ocupação do horário eleitoral é o uso desse espaço para as disputas majoritárias. Apesar de vedado pela legislação, as campanhas para cargos majoritários muitas vezes usam o espaço destinado a deputados ou vereadores para responder os adversários ou promover ataques. Por fim, há um terceiro motivo de desvio da distribuição do espaço no HGPE proporcional, que é a concentração de tempo e espaços mais privilegiados em candidatos considerados "puxadores" de votos. Com a justificativa de aumentar a votação dos partidos ou coligações, esses candidatos - normalmente concorrentes à reeleição, estrelas da mídia ou do esporte - são beneficiados na alocação do recurso tempo de televisão. Apenas com a análise de conteúdo do HGPE proporcional será possível constatar a força dessas distorções comparativamente.

Portanto, a importância do estudo do horário eleitoral em disputas proporcionais começa na identificação da alocação de recursos partidários e vai além. Os programas são espaços oficiais para os partidos expressarem suas prioridades em políticas públicas. Para isso, são planejados e produzidos sob responsabilidade de uma direção geral do partido ou comando das campanhas. No horário eleitoral como um todo, a distribuição do tempo na televisão obedece ao tamanho de suas bancadas no Legislativo. Em linhas gerais, o partido controla seu tempo na televisão, e a subdivisão do mesmo entre os candidatos depende de critérios distributivos, que podem ser mais hierárquicos ou mais igualitários, dependendo da dinâmica das forças internas de cada partido. Assim, é o partido que determina se seus candidatos terão maior ou menor liberdade na divulgação de suas mensagens e, conseqüentemente, prescreve uma maior unidade ou fragmentação na própria imagem que projeta por via da televisão (DIAS, 2005). 
CERVI, E. U. O uso do HPGE como recurso partidário em eleições proporcionais...

Apresentados os argumentos e justificativas para a análise de conteúdo do HGPE como forma de identificar a distribuição de recursos partidários para os candidatos e mecanismo de construção de imagem pública dos postulantes aos cargos legislativos, no próximo tópico são apresentadas as variáveis consideradas relevantes para esse tipo de estudo. Trata-se, portanto, da análise de conteúdos (BAUER \& GASKELL, 2003) veiculados em um momento específico da campanha política, que é o horário eleitoral.

\section{Instrumento para coleta de dados de HGPE proporcional}

A análise de conteúdo é híbrida, reunindo técnicas que permitem estudos quantitativos e qualitativos (BAUER \& GASKELL, 2003; MAHONEY \& GOERTZ, 2006). A unidade de análise aqui é chamada de segmento. No caso de eleições proporcionais, cada segmento é limitado pela presença de um candidato ou orador diferente na tela da TV. Sempre que muda o orador - e na maioria das vezes o orador é o candidato - abre-se um novo segmento. As variáveis que compõem a proposta apresentada aqui se dividem em indexadoras, ou seja, aquelas que têm a função de identificar características distintivas dos candidatos, e em variáveis de conteúdo, também chamadas de elementos semânticos. O primeiro grupo é composto pela data de exibição, tipo de orador, posição no programa, número do candidato, partido do candidato, sexo do candidato, tipo de candidato e duração do segmento em segundos. Com esse conjunto de informações pretende-se traçar um perfil dos candidatos por partido, ou qualquer outra variável independente, no que diz respeito ao tempo ocupado pelos concorrentes, em termos quantitativos, e quanto à posição que ocupam, seja ao longo da campanha, seja dentro de cada programa, em termos qualitativos, para a identificação dos recursos distribuídos. Em suma, as variáveis indexadoras têm o objetivo de identificar o que caracteriza principalmente cada segmento analisado (RAGIN, 1994; CONDE \& ROMÁN, 2005).

O segundo grupo, dos elementos semânticos, é composto pela menção a um partido político, uma etnia, uma profissão, uma região geográfica, uma religião, um tema, se existe ou não apelo direto ao voto; em caso positivo, que tipo de apelo e uso de símbolos, indumentária ou apetrechos externos ao discurso político convencional. Também é proposto o registro sobre a utilização de espaço do horário destinado aos candidatos proporcionais pela disputa majoritária. Nesse caso, é indicada a presença ou não do candidato majoritário e a valência do conteúdo veiculado por ele: se positiva, negativa ou neutra. As variáveis estão apresentadas a seguir. 


\section{a) Variáveis Indexadoras:}

a.1) Data: importante o registro da data de exibição do programa, pois ela permite análises posteriores de séries temporais. A partir de pesquisas de audiência, identifica-se que o HGPE começa em alta nos primeiros dias de programa, apresenta uma queda gradual até as últimas semanas, quando a audiência volta a subir. Então, a curva de atenção destinada aos programas eleitorais apresenta-se em forma de $U$. Sendo assim, se houver uma concentração das aparições de determinados candidatos nos picos de audiência e de outros no período central das apresentações, será um indicativo de que há distribuição desigual desse recurso de campanha;

a.2) Tipo de orador: os oradores dividem-se em quatro categorias. A primeira delas é o próprio "candidato" às eleições proporcionais (deputado federal, estadual - em disputas nacionais - ou vereador - nas municipais). Sempre que aparece um candidato é obrigatória a veiculação do seu número na disputa. A segunda categoria é "líder partidário", quando, no lugar do candidato aparece um integrante da executiva ou o próprio presidente do partido para pedir votos à sigla ou, de maneira genérica, aos candidatos de seu partido. Outra categoria é a de "patrono político", que é todo orador com vínculo à estrutura partidária, mas que não está disputando a eleição e não fala em nome do partido. Podem ser exocupantes de cargos públicos, prefeitos, senadores, governadores ou presidente da república que pedem voto a um concorrente ou aos candidatos de seu partido. Por fim, outra categoria é a de "líder social", no qual se enquadram todos os oradores do HGPE que não são candidatos ou falam em nome da estrutura partidária. São pessoas da sociedade, com destaque ou anônimos, pedindo voto. Pode ser um líder social, ocupante de cargo público não eletivo, um esportista, personalidade reconhecida por suas contribuições profissionais. O que diferencia o líder social do patrono político é que o primeiro não tem vínculo direto e explícito com a sigla partidária, mas sim com uma causa defendida pelo candidato ou com o próprio postulante à vaga;

a.3) Tipo de candidato: essa variável identifica qual o tipo de candidato ao cargo legislativo em disputa, sempre a partir do que é expresso por ele no programa. Portanto, essa categorização só se aplica para os casos em que o tipo de orador for "candidato". Nos demais, não há informação para ser coletada. Os candidatos foram classificados em quatro tipos possíveis. O primeiro é "sem mandato", para aqueles que estão disputando o cargo pela primeira vez e que não ocupam nenhuma posição em órgão estatal por indicação. Aqui se encontram aqueles que não se identificam com cargo público eletivo ou não eletivo. $O$ segundo tipo é de "ocupante de cargo não-eletivo", onde se enquadram todos os candidatos que são secretários municipais, de estado, diretores de estatais, de órgãos por 
CERVI, E. U. O uso do HPGE como recurso partidário em eleições proporcionais...

nomeação política em diferentes escalões de governo. Em seguida estão os candidatos "ocupantes de outro cargo eletivo" que, como exemplo, seria o caso de um vereador disputando uma eleição para deputado federal ou estadual. O mesmo vale para senador em disputa por vaga na Câmara dos Deputados etc. Por fim, o último tipo de candidato é aquele que concorre à "reeleição". Aqui estão todos os concorrentes que já ocupam o cargo em disputa e pretendem a reeleição. O objetivo é verificar se um dos tipos de candidatos é privilegiado no que diz respeito ao tempo e qualidade do espaço ocupado no horário eleitoral;

a.4) Posição no programa: a posição no programa indica sequencialmente qual espaço o candidato ocupa dentro do horário de seu partido ou coligação. Ela é importante, pois os candidatos que estão na "ponta inicial" do programa contam com a atenção extra gerada pelas vinhetas e jingles de transição;

a.5) Número do candidato e partido político: registra-se o número do candidato indicado na tela da tevê. Aqui, o objetivo é meramente de indexação para uso posterior em cruzamentos que necessitem identificar o candidato individualmente. O número permite inferir o seu partido, pois, sempre, os dois primeiros dígitos do concorrente são os números do registro do partido no Tribunal Superior Eleitoral;

a.6) Sexo do candidato: indica se o candidato é do sexo masculino ou feminino. É preciso ressaltar que para a variável sexo existem apenas as duas alternativas citadas acima. Já no caso de gênero há uma série de opções. No entanto, o objetivo aqui é identificar apenas o sexo e não a opção de gênero dos candidatos. A variável sexo é importante para identificar se existe alguma distorção em termos quantitativos e qualitativos no tratamento das mulheres pelo HGPE. Se, por um lado, a literatura da área mostra a existência de uma subparticipação das mulheres nas chapas e coligações partidárias, é preciso avançar para descobrir se elas ocupam menor tempo e espaços menos nobres no horário eleitoral. Se isso ocorre, estamos diante de um tratamento duplamente desigual em relação às candidatas;

a.7) Tempo: marcado em segundos, indica o tempo ocupado pelos segmentos de cada candidato. Ao final do período eleitoral é possível comparar totais e médias de tempo por tipo de orador, tipo de candidato e por sexo do candidato.

\section{b) Elementos Semânticos}

A primeira parte dos elementos semânticos é apresentada, sempre, em pares. Primeiramente, indica-se a presença ou ausência do elemento no segmento de cada candidato. Se for constatada presença, então, a segunda parte é registrar o tipo de elemento citado. 
b.1) Menção a partido político, coligação partidária ou organização social: indica-se presença para quando cita explicitamente o partido/coligação de origem do concorrente ou uma organização social qualquer, ex.: ONG, MST, etc. Sempre que houver esse tipo de menção, registra-se o nome da organização citada. Com isso é possível identificar quais partidos ou organizações sociais mais aparecem nos discursos dos candidatos a cargos legislativos.

b.2) Menção a origem étnica: indica-se presença para quando o candidato cita explicitamente sua ligação com alguma etnia e sua atuação em defesa desse grupo social, tais como a africana, a italiana, a japonesa, a árabe etc;

b.3) Menção a região geográfica: indica-se presença quando o candidato cita uma determinada região do país, estado ou município, apontando que será um representante próprio das demandas dessa região. É mais comum em disputas municipais, quando os concorrentes tendem a se identificar com determinados bairros ou regiões da cidade, mas também ocorre com a citação de regiões específicas de um estado, como a litorânea. Deve-se anotar a região citada pelo concorrente;

b.4) Menção a ocupação ou atividade profissional: Quando o candidato se apresenta como representante de determinada categoria profissional e explicita isso no programa eleitoral, deve ser indicada a menção à atividade e feito o registro do que foi citado. Por exemplo, caso o candidato cite que é agropecuarista, deve ser registrado; da mesma forma ao se apresentar como defensor dos interesses da categoria dos médicos no Congresso Nacional.

b.5) Menção a identificação religiosa: registra-se a religião citada pelo candidato, depois de indicar esse tipo de elemento no discurso. Não se deve confundir identificação religiosa com menção à ocupação. Ocupar a posição de pastor não é considerado identificação religiosa. O candidato só usa o elemento religião quando defende preceitos religiosos de maneira expressa, por exemplo, quando diz que se eleito defenderá a proibição ao aborto por ser uma prática contrária aos preceitos religiosos que defende;

b.6) Apelo ao voto: o apelo ao voto ocorre quando o candidato faz uma solicitação direta e explícita ao eleitor/telespectador. Por exemplo, quando diz "vote em mim, mulher", "conto com você", "ajude-me a vencer mais essa", "venha, você que é jovem, comigo" e qualquer outro tipo de pedido direto. Uma vez indicado o apelo ao voto, deve-se registrar o seu tipo. Existem dez categorias para diferentes tipos de apelo. A primeira é para apelo "não tipificado", quando é abstrato e não faz parte de qualquer das demais categorias. Este é o tipo mais breve: "vote em mim", não tem direcionamento algum para o apelo. O segundo é o apelo ao "voto jovem", quando se dirige à juventude. Em seguida, o apelo à "terceira idade", direcionada aos idosos. Há também o apelo ao "voto consciente", que também é genérico, mas apresenta um qualificativo. Outro tipo é o "voto ideológico", quando expressa aos 
CERVI, E. U. O uso do HPGE como recurso partidário em eleições proporcionais...

simpatizantes de determinada ideologia no desejo de conseguir o voto. Há ainda o apelo ao "voto feminino", dirigido às mulheres; aos "portadores de necessidades especiais", quando destinado a esse segmento. O tipo de apelo ao "voto por identidade cultural" ocorre quando o candidato pede expressamente o voto aos que se aproximam de um padrão cultural identificado como sendo dele. O oitavo tipo de apelo é o destinado ao eleitor "LGBTS ou terceiro gênero". Nesse caso explicita-se o pedido de voto em favor da causa dos direitos homossexuais. O penúltimo tipo de apelo é ao "voto religioso", quando o candidato pede voto diretamente a fiéis ou seguidores de determinado credo religioso. Por fim, há o tipo de apelo por "moral e valores", quando ocorre em defesa de determinados padrões de comportamento, ética, pelo trabalho em favor dos necessitados etc;

b.7) Tema: além de se apresentar a partir de menções a diferentes segmentos sociais e fazer apelo direto ao voto, os candidatos também podem discutir temas de interesse público que fazem parte do debate político. Como nem todos têm tempo ou disposição para dar um caráter temático às suas participações no HGPE é preciso indicar quem fala e sobre quais temas se fala no horário eleitoral. Para tanto foram estabelecidas 15 categorias temáticas no livro de códigos para o registro dos temas abordados. São elas: 1) nenhum, quando o candidato não trata de tema algum em seu espaço no HGPE; 2) saúde; 3) economia; 4) violência ou segurança pública; 5) político-institucional, quando trata de relações entre governo e oposição, fiscalização do executivo etc; 6) meio ambiente; 7) infra-estrutura; 8) ético-moral; 9) esporte e lazer; 10) turismo; 11) cultura; 12) educação básica e creches; 13) educação secundária, técnica e superior; 14) cardápio, quando o candidato fala de mais um tema, sem priorizar um, especificamente e 15) outro, caso o tema tratado no segmento não se enquadre nos anteriores;

b.8) Uso pela campanha majoritária: indica que o segmento foi usado para tratar de temas envolvendo a disputa ou candidatos às eleições majoritárias. Além de indicar se foi ou não usado para esse fim, deve-se indicar, ainda, se houve citação direta de um ou mais candidatos majoritários. Havendo citação de um dos concorrentes à disputa majoritária anota-se, então, a sua valência, se positiva, negativa ou neutra. Por exemplo, o HGPE dos candidatos a deputado federal de determinado partido pode ser usado para falar sobre as características positivas do candidato à presidência dessa sigla. No caso, com citação direta, a valência seria positiva; se usado em relação ao candidato adversário, apontando alguma falha ou deslize moral, a valência seria negativa. 


\section{c) Elementos Simbólicos}

Os elementos simbólicos são caracterizados por acessórios visuais que ajudam a compor a imagem que o candidato quer transmitir para o eleitor/telespectador. Divide-se em dois grandes grupos:

c.1) Presença de símbolos na tela: registra-se quando o candidato apresenta símbolos variados ligados à sua imagem. Pode ser um símbolo partidário, que represente uma profissão ou etnia. Nesse caso, registra-se a presença do símbolo e indica-se qual é o símbolo usado;

c.2) Uso de apetrechos atípicos à política: ocorre quando o candidato apresenta-se no horário eleitoral portando elementos visuais pouco comuns para o debate político convencional. Registra-se a presença do apetrecho e depois indicase qual a indumentária que aparece. É o caso de candidatos com roupas típicas regionais, por exemplo; ou um concorrente que se apresenta como médico vestindo jaleco, ou mesmo uma candidata que veste uma cinta-liga para indicar determinado posicionamento contra preconceitos machistas na política.

\section{Aplicação da tipologia a candidatos a deputado federal pelo Estado do Paraná, em 2006}

Esta seção apresenta os resultados de análises iniciais aplicadas ao HGPE de candidatos a deputado federal pelo Estado do Paraná nas eleições de 2006. Naquele ano, foram apresentados 258 concorrentes às 30 vagas paranaenses na Câmara dos Deputados. A seção discute apenas as informações coletadas sobre a distribuição do horário eleitoral pelos partidos políticos aos candidatos; o objetivo não é tratar da utilização desse espaço para a construção de imagens públicas pelos concorrentes. Esse ponto ficará para trabalhos futuros.

O objetivo é verificar como os partidos políticos distribuem esse recurso de campanha denominado tempo de HGPE a seus candidatos, se a distribuição é feita de maneira homogênea e equitativa, ou se algum grupo de concorrentes com características específicas consegue ocupar mais tempo de campanha. Para desenvolver essas análises duas características principais dos candidatos são consideradas: sexo e tipo. Primeiramente, os concorrentes foram divididos entre homens e mulheres, o que permitirá verificar a hipótese de que as mulheres candidatas têm menos espaço no HGPE do que os homens. Em seguida, será verificado qual o espaço ocupado proporcionalmente por quatro tipos de candidatos: o "sem mandato", aquele que está disputando pela primeira vez; o "ocupante de cargo não-eletivo", quando o candidato identifica-se como responsável por alguma atividade pública formalmente ligada ao Estado, fruto de indicação política, tal secretário de Estado, ministro, presidente ou diretor de empresa 
pública; o "ocupante de outro cargo eletivo", quando está no exercício do mandato eletivo (não como deputado federal), por exemplo, prefeito, governador de Estado ou vereador; e o "candidato à reeleição", se o concorrente identifica-se como sendo um dos atuais ocupantes das vagas do estado na Câmara dos Deputados e postula a reeleição.

Tomando como ponto de partida que "sexo" e "tipo de candidato" são variáveis dependentes, pretende-se identificar se o número de vezes que aparecem e o tempo ocupado pelos candidatos, assim como a sua distribuição ao longo do período de campanha, apresentam alguma tendência. Para tanto, serão consideradas apenas as informações extraídas de 18 programas de HGPE analisados e que foram ao ar entre os dias 17 de agosto e 28 de setembro de 2006. Cada programa teve 30 minutos de duração, com tempo distribuído entre os partidos políticos pelo TSE. Como a duração dos programas varia entre os partidos, não é possível fazer comparações diretas, em termos absolutos, entre as siglas, limitando-nos à análise interna da distribuição dos espaços de cada partido ou fazendo verificações gerais, a partir do horário como um todo. Dessa forma, o estudo da presença dos candidatos entre os partidos só pode ser feito relativamente, em termos de percentuais. No segundo caso, identificamos padrões adotados pela elite partidária em geral e comparativamente; enquanto no primeiro caso, verificamos o tratamento dispensado por cada partido isoladamente aos seus candidatos. Também analisamos a distribuição qualitativa do recurso "horário de televisão" entre os candidatos a partir de dois testes. O primeiro indica se há ou não crescimento da presença de algum grupo de candidatos ao longo do tempo (MORETTIN \& TOLOI, 2004), pois, sabe-se que o HGPE das últimas semanas de campanha tem maior audiência que os primeiros programas. O outro teste que verifica a qualidade do espaço distribuído analisa se há diferenças entre os candidatos que aparecem com e sem falas próprias no HGPE. Para tanto, são divididos entre os que podem apresentar suas próprias propostas no horário eleitoral e os que ficam "mudos" na tela, enquanto um locutor fala o nome e número do concorrente.

HGPE e a representação feminina nas campanhas eleitorais

A primeira hipótese a ser testada é se as mulheres recebem o mesmo tratamento que os candidatos no HGPE e, por conseqüência, se têm acesso a esse recurso de campanha na mesma proporção dos homens. A legislação eleitoral determina que pelo menos um terço das vagas em disputa sejam destinadas a candidatos do mesmo sexo (homens ou mulheres). No entanto, para as mulheres, raramente esse percentual é alcançado. Os dirigentes partidários afirmam que não há mulheres interessadas nas vagas. De toda forma, em 2006, no Paraná, foram 
registrados 258 candidatos a deputado federal, dos quais 232 do sexo masculino e 26 do sexo feminino, o que representa $10,1 \%$ de candidatas, conforme dados do TSE, bem abaixo dos 33,3\% previstos em lei.

A questão aqui é saber se essa subrepresentação do número de concorrentes mulheres é reduzida ou ampliada nos espaços de HGPE. A Tabela 1 mostra que, no geral, há uma ampliação da subparticipação das mulheres na campanha eleitoral, quando considerado o número de segmentos em que elas aparecem e o tempo ocupado pelas candidatas em geral. Enquanto temos $10,1 \%$ de mulheres na disputa, elas aparecem em apenas 7,6\% do total de segmentos e ocupam $6,6 \%$ do total de tempo do horário eleitoral, medido em segundos.

Tabela 1

Distribuição dos candidatos por sexo e tempo no HGPE

\begin{tabular}{|l|r|r|r|r|r|r|}
\hline \multirow{2}{*}{ Sexo } & \multicolumn{2}{|c|}{ Candidatos } & \multicolumn{2}{c|}{ Segmentos } & \multicolumn{2}{c|}{ Segundos } \\
\cline { 2 - 7 } & $\mathbf{N}$ & \multicolumn{1}{c|}{$\boldsymbol{N}$} & $\mathbf{N}$ & \multicolumn{1}{c|}{$\boldsymbol{N}$} & \multicolumn{1}{c|}{$\mathbf{N}$} & \multicolumn{1}{c|}{$\%$} \\
\hline Homem & 232 & 89,9 & 1100 & 92,4 & 17359 & 93,40 \\
\hline Mulher & 26 & 10,1 & 90 & 7,6 & 1226 & 6,60 \\
\hline Total & 258 & 100,0 & 1190 & 100,0 & 18585 & 100,0 \\
\hline
\end{tabular}

Nota: Teste t para diferença de médias entre sexo do candidato e tempo total por dia (segundos) resulta em estatística $\mathrm{t}=6,750$ e Sig. $=0,000$.

Os dados mostram que, se não existem mulheres em número suficiente para ocuparem as vagas destinadas a elas nas chapas partidárias, aquelas que se propõem a participar recebem um tratamento desigual em relação aos candidatos. Essa condição é confirmada pelo teste $t$ de diferenças de médias que, nesse caso, visa identificar se as médias de tempos totais ocupados pelos homens e pelas mulheres no HGPE apresentam diferenças estatisticamente significativas. 0 coeficiente $t$ de 6,750, com nível de significância bem abaixo do limite crítico (sig=0,000) confirma a hipótese de que as diferenças de médias nos tempos não são aleatórias. Os homens têm tempos significativamente superiores que as mulheres no HGPE.

Para complementar a análise, a Tabela 2 mostra a distribuição das mulheres no HGPE, separada por partido político. Na Tabela, em que estão incluídos apenas os partidos cujas candidatas apareceram em um dos programas analisados, é possível comparar as diferenças entre candidatos homens e mulheres para o número de segmentos e total de tempo ocupado pelos grupos. A menor diferença proporcional entre números de candidatos ocorre no PSOL, que tem três homens para cada mulher concorrendo a deputado federal; o PRTB, PT e PMDB obtiveram médias próximas de sete homens para cada mulher na disputa, e a maior 
CERVI, E. U. O uso do HPGE como recurso partidário em eleições proporcionais...

desproporção ocorreu com o PDT, que apresentou 18 homens para apenas uma mulher na chapa.

Tabela 2

Proporção de sexo por partido político e espaço no HGPE

\begin{tabular}{|l|r|r|r|r|r|r|r|r|r|}
\hline & \multicolumn{9}{|c|}{ Sexo do candidato } \\
\cline { 2 - 11 } & \multicolumn{3}{|c|}{ Homem } & \multicolumn{3}{c|}{ Mulher } & \multicolumn{2}{|c|}{ Rel. Homem/Mulher } \\
\cline { 2 - 11 } & $\begin{array}{r}\mathbf{N}^{\circ} \\
\text { Cand. }\end{array}$ & $\begin{array}{c}\mathbf{N}^{\circ} \\
\text { Seg. }\end{array}$ & $\begin{array}{c}\text { Total } \\
\text { tempo }\end{array}$ & $\begin{array}{c}\mathbf{N}^{\circ} \\
\text { Cand. }\end{array}$ & $\begin{array}{c}\mathbf{N}^{\circ} \\
\text { Seg. }\end{array}$ & $\begin{array}{c}\text { Total } \\
\text { tempo }\end{array}$ & $\begin{array}{c}\text { Dif. } \mathbf{N}^{\circ} \\
\text { cand. }\end{array}$ & $\begin{array}{c}\text { Dif. } \\
\mathbf{N}^{\circ} \\
\text { seg. }\end{array}$ & $\begin{array}{c}\text { Dif. Tot. } \\
\text { Temp }\end{array}$ \\
\hline PV & 31 & 67 & 705 & 5 & 5 & 54 & 6,2 & 13,4 & 13,0 \\
\hline PPS & 30 & 167 & 2364 & 3 & 22 & 280 & 10,0 & 7,5 & 8,4 \\
\hline PMDB & 23 & 81 & 1844 & 3 & 8 & 148 & 7,6 & 10,1 & 12,4 \\
\hline PT & 22 & 146 & 3405 & 3 & 11 & 252 & 7,30 & 13,2 & 13,5 \\
\hline PSDB & 18 & 172 & 1857 & 2 & 15 & 202 & 9,0 & 11,4 & 9,1 \\
\hline PDT & 18 & 246 & 4356 & 1 & 10 & 128 & $\mathbf{1 8 , 0}$ & $\mathbf{2 4 , 6}$ & $\mathbf{3 4 , 0}$ \\
\hline PRTB & 7 & 91 & 358 & 1 & 16 & 58 & 7,0 & 5,6 & 6,1 \\
\hline PSOL & 3 & 7 & 159 & 1 & 3 & 104 & $\mathbf{3 , 0}$ & $\mathbf{2 , 3}$ & $\mathbf{1 , 5}$ \\
\hline
\end{tabular}

Para a maioria dos partidos, a desproporção aumenta quando consideradas as diferenças no número de segmentos ocupados por homens e mulheres. Em apenas três casos isso se inverte: no PPS, enquanto a relação é de 10 candidatos para cada mulher, em número de segmentos no HGPE essa diferença cai para 7,5; no PRTB, a relação de candidaturas é de sete homens para cada mulher e em número de segmentos no horário eleitoral é de 5,6, e, no PSOL, a desproporção de candidaturas estabelecida em 3, passa para 2,3 em número de segmentos. Em todos os demais partidos, o número de segmentos no HGPE com mulheres é proporcionalmente ainda menor do que o total de candidaturas. No PV, o valor chega a dobrar: enquanto há 6,2 homens para cada candidata pelo partido, nota-se 13,4 segmentos para o sexo masculino no HGPE contra cada segmento destinado às mulheres. Porém, a maior desproporção fica, ainda, por conta do PDT, passando de 18 homens por mulher entre as candidaturas, para 24,6 segmentos masculinos para cada segmento feminino no horário eleitoral.

Quando se analisa o tempo total ocupado segundo o sexo dos candidatos e o partido, a desproporção aumenta ainda mais, com a exceção de duas siglas, PSDB e PSOL. No PSDB, a desproporção que era de 11 para um no número de segmentos, cai para 9,1 segundos no HGPE para homens para cada segundo destinado às candidatas. Essa desproporção fica muito próxima da relação de 
candidaturas, que é de 9 por 1 na sigla. No PSOL, o partido apresentou três candidatos homens e apenas uma mulher, tem uma diferença em número de segmentos de 2,3 em favor dos homens e de 1,5 em total de segundos. Isso significa que no PSOL a sua candidata teve mais espaço relativo do que os concorrentes do sexo masculino. Esse foi o único caso de desproporção favorável às mulheres dentre os partidos analisados aqui.

$\mathrm{Na}$ maioria dos partidos, a desproporção do tempo total entre homens e mulheres aumenta a subparticipação feminina no HGPE. O caso mais evidente é do PDT, que tem um acréscimo de 24,6 segmentos com homens para cada um com mulher, passando a 34 segundos no total destinados aos candidatos a Deputado Federal para cada um das candidatas. O único partido a inverter essa lógica, dando maior participação às candidatas no HGPE foi o PSOL.

Como os índices de audiência do horário eleitoral não são lineares, tendendo a aumentar nas últimas semanas em relação ao início das transmissões, a análise global das distribuições de tempo e número de segmentos não é suficiente para identificar o tratamento dado a homens e mulheres nesse espaço. Se houver aumento na presença de um dos tipos de candidatos no final do período, isso significa que ele tem chance de ser assistido por um número maior de eleitores e, portanto, seria beneficiado. Os Gráfico la e 1 b mostram a reta da tendência de tempo para homens e mulheres no HGPE, além de algumas estatísticas de séries temporais. 


\section{Gráfico 1}

Tempo no HGPE por sexo do candidato ao longo do período

\section{1a_homens}

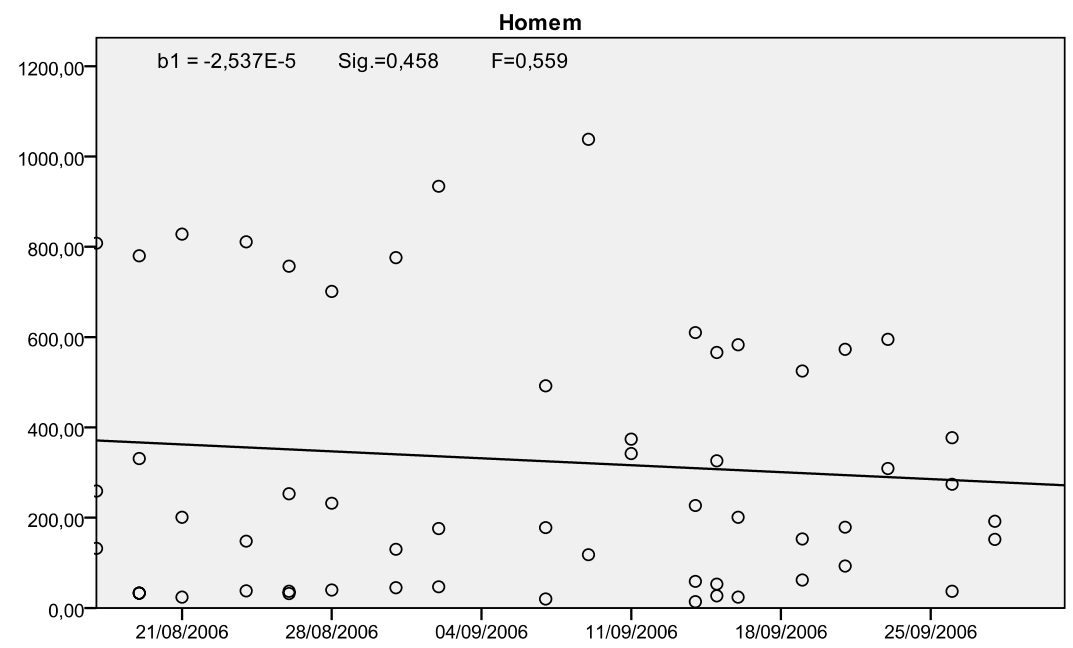

\section{1b_mulheres}

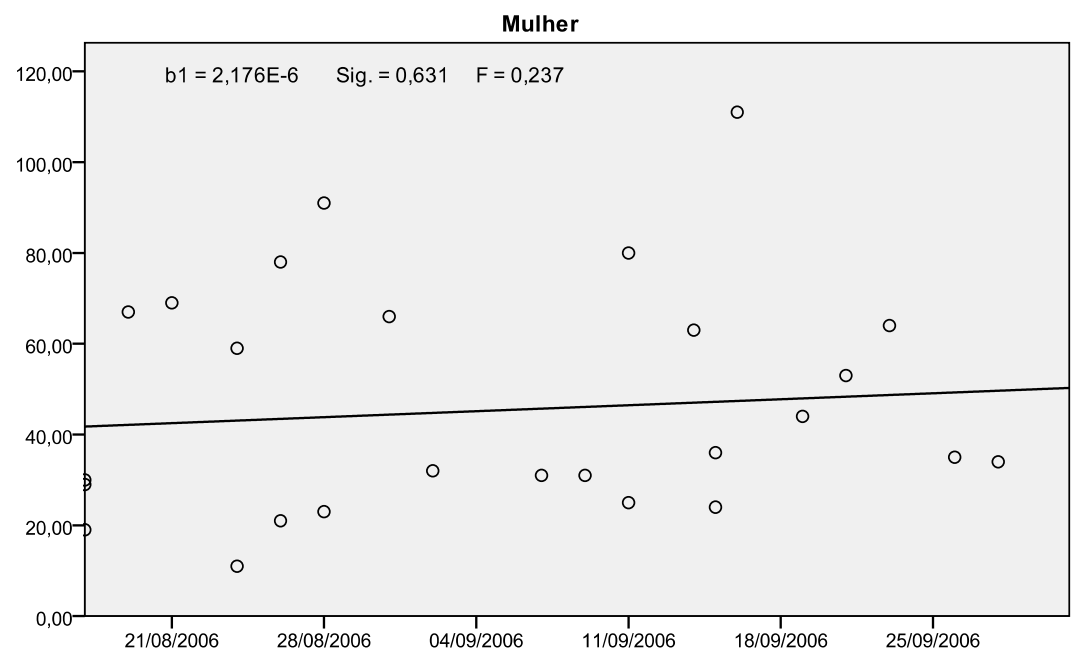


As retas indicam que no caso dos homens há uma tendência decrescente de participação no tempo total de cada programa ao longo do tempo. No sentido inverso, o tempo destinado às mulheres cresce nas últimas semanas. No entanto, o impacto das diferenças é muito pequeno, com uma estatística $F$ muito baixa para os dois grupos (0,559 para homens e 0,237 para mulheres). Embora os níveis de significância para ambos os grupos fiquem acima do limite crítico, como estamos trabalhando com toda a população e esse indicador revela o grau de segurança em "extrapolar" os resultados a partir de uma amostra, podemos continuar analisando os resultados dos testes. Para tanto, o coeficiente mais importante é a expectativa de Beta (b1). Esse coeficiente (b1 nos Gráficos 1a e 1b), que indica a expectativa de encontrar integrantes de determinado grupo de maneira aleatória ao longo do tempo, é muito baixo tanto para os homens, quanto para as mulheres. No entanto, a diferença está no fato de que nos candidatos do sexo masculino ele é negativo (2,537E-5) e positivo para o feminino (2,176E-6), ou seja, é menos provável encontrar um segmento com um candidato conforme se aproxima o final do período e mais provável encontrar um com uma candidata.

Outra característica qualitativa do HGPE sem diferenças significativas quanto ao sexo do candidato é a ocorrência de fala própria do concorrente ou se ele apenas aparece no vídeo, com indicação de nome e número. Normalmente, os concorrentes com menor espaço não conseguem apresentar uma proposta de trabalho mais detalhada em função do curto espaço de tempo e da ausência de falas próprias. A Tabela 3 mostra que, do total de segmentos analisados, $70 \%$ no total apresentaram candidatos com fala. Em relação aos homens, $70,5 \%$ dos segmentos fora com fala; no caso das mulheres, os percentuais alteram-se um pouco, com $63,3 \%$ com fala.

\section{Tabela 3}

\section{Relação entre segmentos com fala e sexo do candidato}

\begin{tabular}{|l|c|c|c|c|}
\hline \multirow{3}{*}{ Sexo } & \multicolumn{3}{|c|}{ Candidato com fala } \\
\cline { 2 - 5 } & \multicolumn{2}{|c|}{ Não } & \multicolumn{2}{c|}{ Sim } \\
\cline { 2 - 5 } & $\mathbf{N}$ & $\mathbf{\%}$ & $\mathbf{N}$ & $\mathbf{\%}$ \\
\hline Homem & 324 & 29,5 & 776 & 70,5 \\
\hline Mulher & 33 & 36,7 & 57 & 63,3 \\
\hline Total & 357 & 30,0 & 832 & 70,0 \\
\hline
\end{tabular}

Nota: q-quadrado $p=1,044(0,153)$ 
CERVI, E. U. O uso do HPGE como recurso partidário em eleições proporcionais...

Apesar das diferenças percentuais, o teste de médias para variáveis categóricas q-quadrado de Pearson não se mostrou significativo (nível de significância muito acima do limite crítico, sig=0,153, e Pearson de apenas 1,044), o que demonstra a inexistência de relação estatística entre segmento com ou sem fala e sexo do candidato, considerando todo o universo analisado.

Até aqui, as análises realizadas demonstraram que as mulheres são subrepresentadas em termos de número de candidatos e a desigualdade proporcional tende a aumentar quando se analisa a sua participação quantitativa no HGPE dos partidos, de maneira geral. Vimos, também, que existem algumas exceções. No entanto, em termos qualitativos, considerando a distribuição no período de maior audiência, as candidatas conseguiram apresentar um pequeno ganho, além do fato de não existir diferença estatisticamente significativa entre segmento com ou sem fala entre homens e mulheres.

Ressalte-se que esses achados são insuficientes para permitir qualquer afirmação sobre o tratamento destinado às mulheres pelos partidos políticos. Por exemplo, não é possível dizer que o HGPE intensifica as diferenças entre candidatos homens e mulheres, pois há uma diferença significativa de homens já ocupando cargos importantes nas estruturas partidárias em relação às mulheres. Além disso, como demonstra o próximo tópico, a presença em mandato eletivo ou cargo na estrutura partidária é um forte preditor de presença no HGPE. Também não é possível analisar a relação de gênero entre os partidos políticos a partir de uma única campanha em uma unidade da federação. Devemos considerar que existem fatores conjunturais interferindo nas composições das chapas de candidatos que não podem ser identificadas em uma análise de conteúdo do horário eleitoral. Assim, é possível que em 2006 o PDT do Paraná não tenha conseguido um número adequado de candidatas por conta de problemas na frente feminina do partido; ou que o PSOL tenha seguido a determinação nacional de dar preferência para mulheres e isso o diferencie das demais siglas no Estado.

Um fator inquestionável que não aparece diretamente na distribuição de tempo do HGPE é que a apropriação desigual desse recurso dentro de um partido resulta de uma disputa de forças internas, de grupos e indivíduos. É necessário descobrir as origens dessa desigualdade, objeto que esse texto não desenvole, pois os instrumentos analíticos dispostos aqui são incapazes de oferecer respostas.

\section{Candidatos sem mandato têm menos tempo de HGPE}

Uma outra forma de identificar possíveis critérios partidários para distribuição de horário eleitoral dá-se a partir dos tipos de candidatos. Se o tempo de HGPE for destinado estrategicamente pelas cúpulas partidárias aos concorrentes com maior chance de vitória, então os candidatos à reeleição ou já ocupantes de 
cargos eletivos devem ter maior aparição nesse espaço. Ou, alternativamente, o tempo no HGPE pode ser distribuído de maneira proporcional a todos os candidatos, independente do grau de visibilidade política anterior à campanha. 0 TSE identifica os candidatos segundo dois grandes grupos, a partir das informações prestadas pelos próprios concorrentes: candidato à eleição ou à reeleição. Na coleta de informações do HGPE, aqueles que não se identificam como concorrentes à reeleição foram subdivididos em três grupos, já detalhados anteriormente: sem mandato, ocupante de cargo não-eletivo e ocupante de outro cargo eletivo. Com esses grupos pode-se identificar possíveis favorecimentos no HGPE não apenas aos ocupantes do mesmo cargo, mas a outros integrantes da elite política-partidária, distinguindo-os daqueles que estão "aparecendo" pela primeira vez na esfera político-eleitoral.

Segundo dados oficiais do TSE, em 2006 a disputa pelas vagas de deputado federal do Estado do Paraná contou com $225(86,1 \%)$ de candidatos à eleição e 332 $(13,9 \%)$ de concorrentes à reeleição. A Tabela 4 divide os candidatos à eleição entre aqueles sem mandato, ocupantes de cargo não-eletivo e os ocupantes de cargo eletivo para a comparação entre o número de segmentos destinados a cada categoria e o tempo total em segundos. Os dados mostram que, quanto aos candidatos à reeleição, o percentual de segmentos fica muito próximo da participação deles no total: enquanto há $13,9 \%$ de concorrentes à reeleição, eles ocupam $13,7 \%$ do total de segmentos. No entanto, o percentual de tempo destinado a essa categoria é bem maior, ficando em $20,5 \%$.

\section{Tabela 4}

\section{Distribuição dos concorrentes por tipo de candidatura em 2006}

\begin{tabular}{|c|c|c|c|c|c|c|}
\hline Tipo de Candidato & $\begin{array}{c}\mathrm{N}^{\circ} \\
\text { candid. }\end{array}$ & $\begin{array}{c}\% \\
\text { candid. }\end{array}$ & $\begin{array}{c}\mathrm{N}^{0} \\
\text { segment. }\end{array}$ & $\begin{array}{c}\% \\
\text { segment. }\end{array}$ & $\begin{array}{c}\text { Total } \\
\text { segundos }\end{array}$ & $\begin{array}{c}\% \\
\text { segundos }\end{array}$ \\
\hline Sem mandato & \multirow{3}{*}{225} & \multirow{3}{*}{86,1} & 960 & 80,8 & 13.383 & 72,1 \\
\hline Ocupante de cargo não-eletivo & & & 12 & 1,0 & 273 & 1,5 \\
\hline $\begin{array}{l}\text { Ocupante de outro cargo } \\
\text { eletivo }\end{array}$ & & & 53 & 4,5 & 1.108 & 5,9 \\
\hline Candidato à reeleição & 33 & 13,9 & 163 & 13,7 & 3.789 & 20,5 \\
\hline Total & 258 & 100,0 & 1188 & 100,0 & 18.553 & 100,0 \\
\hline
\end{tabular}

Nota: Teste q-quadrado entre distribuição de candidatos e segmentos mostra-se não-significativo (sig. $=0,953$ ). Para o q-quadrado entre candidatos e tempo em segundos o resultado fica em sig=0,056

\footnotetext{
2 Embora a bancada do Paraná em 2006 tivesse apenas 30 vagas em disputa, 33 candidatos indicaram estar concorrendo à reeleição. Isso ocorre porque vários suplentes de 2002 que assumiram vaga temporariamente no congresso registraram-se no TSE como candidatos à reeleição.
} 
Em relação aos candidatos à eleição, há uma desproporção entre o percentual de segundos e de segmentos entre os sem mandato, quando comparados às demais categorias. Enquanto os sem mandato ficam com 80,8\% dos segmentos, o percentual em segundos desse grupo cai para $72,1 \%$ do total, e os ocupantes de cargo não-eletivo, apresentam a maior diferença proporcional, passando de $1 \%$ dos segmentos para $1,5 \%$ do tempo total. Apesar do valor absoluto baixo, a diferença entre percentual de segmentos e tempo total representa exatos $50 \%$ a mais de tempo. No caso dos ocupantes de outros cargos eletivos, também há uma diferença positiva entre tempo total ocupado e número de segmentos, passando de 4,5\% de segmentos para 5,9\% do tempo total.

Para verificar a consistência das distribuições, foram realizados dois testes de independência para variáveis categóricas, q-quadrado de Pearson. O primeiro deles testou se a distribuição da relação entre o número de segmentos e tipo de candidatos é estatisticamente significativo, e o resultado obteve nível de significância de 0,953, bastante acima do limite crítico, não indicando qualquer relação estatisticamente relevante entre as variáveis. Porém, o segundo teste, entre tipo de candidatura e tempo total em segundos mostrou uma relação muito mais consistente, com nível de significância de 0,056, sobre o limite crítico para intervalo de confiança de 95\%, o que permite dizer com certo grau de segurança que a distribuição do tempo total entre os candidatos não foi aleatória. Proporcionalmente e em respectiva ordem decrescente, há mais tempo destinado a candidatos à reeleição, ocupante de cargo eletivo, de cargo não-eletivo e sem mandato.

Analisando o comportamento de cada partido por tipo de candidaturas, no caso de concorrentes sem mandato, a maior diferença em relação à média percentual do número de segmentos $(76,8 \%)$ ocorre com o PT, que destina apenas $53,8 \%$ de seus segmentos a candidatos sem mandato (Tabela 5). Em relação ao tempo total, o PT é o partido que apresenta o menor percentual destinado a candidatos sem mandato (52,8\%), contra uma média geral de $72,1 \%$ de segundos entre todos os partidos. Cabe destacar que na Tabela 5 foram incluídos apenas os partidos políticos que apresentaram pelos menos dois tipos de candidatos nos programas analisados. Aqueles em que só aparecem candidatos sem mandato, por exemplo, foram excluídos. Em relação aos concorrentes que ocupam cargos nãoeletivos, a maior desproporção em relação à média geral de $1 \%$ do total ficou por conta do PSDB, que destinou 3,7\% de seus segmentos a esse tipo de concorrente. Em relação à média de $1,5 \%$ de tempo total destinado aos ocupantes de cargos não-eletivos, o PSDB chegou a $8,6 \%$ do seu tempo total a esse tipo de concorrente.

Para a terceira tipologia de candidaturas, de concorrentes que ocupam outros cargos eletivos, na média, foram destinados 5,4\% dos segmentos e 5,9\% do tempo total. No caso do número de segmentos, a maior desproporção ocorreu com 
o PT, que destinou $10,2 \%$ de seu total a candidatos que ocupam outro cargo eletivo. Em relação ao tempo em segundos, o PMDB apresentou a maior diferença em relação ao percentual médio, chegando a $9,8 \%$ do total destinado aos candidatos que ocupam outros cargos eletivos. No último tipo, candidatos à reeleição, são identificadas as maiores diferenças proporcionais. Enquanto, no total, o número de segmentos desse grupo representa $16,6 \%$ do universo, o PT destinou $35,4 \%$ de seus segmentos a candidatos à reeleição (Tabela 5), sendo que o mesmo ocorre com o tempo em segundos. No total, $20,5 \%$ do tempo do HGPE ficaram com concorrentes à reeleição. No caso do PT, esse número sobe para $38 \%$. No caso do PPS, é o único partido que inverte a desproporção, destinando menos segmentos e tempo em segundos para os candidatos à reeleição, respectivamente, $9,1 \% \mathrm{e}$ $13,8 \%$.

\section{Tabela 5}

Número de segmentos e tempo por tipo de candidato e partido 2006

\begin{tabular}{|c|c|c|c|c|c|c|c|c|}
\hline \multirow{3}{*}{ Partido } & \multicolumn{8}{|c|}{ Tipo de Candidato } \\
\hline & \multicolumn{2}{|c|}{ Sem mandato } & \multicolumn{2}{|c|}{$\begin{array}{c}\text { Ocupante de cargo } \\
\text { não-eletivo }\end{array}$} & \multicolumn{2}{|c|}{$\begin{array}{c}\text { Ocupante de outro } \\
\text { cargo eletivo }\end{array}$} & \multicolumn{2}{|c|}{$\begin{array}{l}\text { Candidato à } \\
\text { reeleição }\end{array}$} \\
\hline & $\mathrm{N}^{\circ}$ segm. & Tot. seg. & $\mathbf{N}^{\circ}$ segm. & Tot. seg. & $\mathrm{N}^{0}$ segm. & Tot. seg. & $\mathrm{N}^{\circ}$ segm. & Tot. seg. \\
\hline PDT & $\begin{array}{r}214 \\
(83,6) \\
\end{array}$ & $\begin{array}{r}3339 \\
(74,5) \\
\end{array}$ & & & $\begin{array}{r}9 \\
(3,5) \\
\end{array}$ & $\begin{array}{r}233 \\
(5,2) \\
\end{array}$ & $\begin{array}{r}33 \\
(12,9) \\
\end{array}$ & $\begin{array}{r}912 \\
(20,3) \\
\end{array}$ \\
\hline PT & $\begin{array}{r}85 \\
(53,8) \\
\end{array}$ & $\begin{array}{r}1928 \\
(52,8) \\
\end{array}$ & $\begin{array}{r}1 \\
(0,6) \\
\end{array}$ & $\begin{array}{r}22 \\
(0,6) \\
\end{array}$ & $\begin{array}{r}16 \\
(10,2)\end{array}$ & $\begin{array}{r}317 \\
(8,6) \\
\end{array}$ & $\begin{array}{r}56 \\
(35,4) \\
\end{array}$ & $\begin{array}{r}1390 \\
(38,0) \\
\end{array}$ \\
\hline PMDB & $\begin{array}{r}54 \\
(60,7) \\
\end{array}$ & $\begin{array}{r}1206 \\
(60,5) \\
\end{array}$ & $\begin{array}{r}1 \\
(1,1) \\
\end{array}$ & $\begin{array}{r}27 \\
(1,3) \\
\end{array}$ & $\begin{array}{r}8 \\
(8,9) \\
\end{array}$ & $\begin{array}{r}195 \\
(9,8)\end{array}$ & $\begin{array}{r}26 \\
(29,3) \\
\end{array}$ & $\begin{array}{r}564 \\
(28,4) \\
\end{array}$ \\
\hline PPS & $\begin{array}{r}155 \\
(82,9) \\
\end{array}$ & $\begin{array}{r}1999 \\
(76,6) \\
\end{array}$ & $\begin{array}{r}3 \\
(1,6)\end{array}$ & $\begin{array}{r}46 \\
(1,7) \\
\end{array}$ & $\begin{array}{r}12 \\
(6,4)\end{array}$ & $\begin{array}{r}207 \\
(7,9)\end{array}$ & $\begin{array}{r}17 \\
(9,1) \\
\end{array}$ & $\begin{array}{r}360 \\
(13,8) \\
\end{array}$ \\
\hline PRTB & $\begin{array}{r}106 \\
(99,0) \\
\end{array}$ & $\begin{array}{r}412 \\
(99,0) \\
\end{array}$ & & & & & $\begin{array}{r}1 \\
(1,0)\end{array}$ & $\begin{array}{r}4 \\
(1,0) \\
\end{array}$ \\
\hline PSDB & $\begin{array}{r}144 \\
(77,0) \\
\end{array}$ & $\begin{array}{r}1196 \\
(58,1) \\
\end{array}$ & $\begin{array}{r}7 \\
(3,7) \\
\end{array}$ & $\begin{array}{r}178 \\
(8,6) \\
\end{array}$ & $\begin{array}{r}8 \\
(4,3) \\
\end{array}$ & $\begin{array}{r}156 \\
(7,6) \\
\end{array}$ & $\begin{array}{r}28 \\
(15,0) \\
\end{array}$ & $\begin{array}{r}529 \\
(25,7) \\
\end{array}$ \\
\hline TOTAL* & $\begin{array}{r}758 \\
(76,8) \\
\end{array}$ & $\begin{array}{l}13383 \\
(72,1)\end{array}$ & $\begin{array}{r}12 \\
(1,2)\end{array}$ & $\begin{array}{r}273 \\
(1,5)\end{array}$ & $\begin{array}{r}53 \\
(5,4) \\
\end{array}$ & $\begin{array}{l}1108 \\
(5,9)\end{array}$ & $\begin{array}{r}161 \\
(16,6)\end{array}$ & $\begin{array}{r}3759 \\
(20,5)\end{array}$ \\
\hline
\end{tabular}

Nota: 0 q-quadrado para total de segmentos e tempo total dos partidos políticos apresenta sig. $=0,180$.

*Os totais na tabela representam apenas os valores dos partidos políticos incluídos na tabela.

O teste de diferença de médias para os números de segmentos por tempo em segundos por tipo de candidato não se mostrou estatisticamente significativo, ficando com sig. $=0,180$, bastante acima do limite crítico para um intervalo de confiança de $95 \%$. Portanto, não se pode afirmar que haja uma diferença real entre a distribuição total de segmentos e de tempo entre os tipos de candidaturas. Quando aplicamos um teste post-hoc em Análise de Variância (Anova), para identificar diferenças estatísticas entre os tipos de candidatos por tempo destinado 
CERVI, E. U. O uso do HPGE como recurso partidário em eleições proporcionais...

pelos partidos, obtemos alguns resultados significativos em três partidos políticos, apenas. O resultado geral do teste apresenta uma estatística $F=37,92$ (sig.=0,000), no entanto, essa relação é significativa para PDT, PPS e PSDB, com resultados distintos para cada um deles.

A Tabela 6 mostra que a similaridade entre os três partidos com resultados significativos é a direção da relação. Em todos os casos _PDT, PPS e PSDB_a média de tempo para concorrentes sem mandato é significativamente menor que a das demais categorias. Também, nos três casos, aparece o tipo "ocupante de outro cargo eletivo" como detentor de média de tempo superior à média dos concorrentes sem mandato. Para o PPS, essa é a única relação significativa, ou seja, candidato sem mandato do PPS teve menos tempo que ocupante de outro cargo eletivo. Para - PDT, além da relação anterior, também ocorre uma diferença favorável a candidato à reeleição, com -12,034 segundos de diferença e nível de significância de 0,000; ou seja, aqui os concorrentes sem mandato perdem espaço para outros dois tipos de candidatos. No PSDB, os "sem mandato" têm tempo de HGPE significativamente menor que todas as demais categorias, sendo que a maior diferença fica por conta de ocupante de cargo não-eletivo, -17,123 segundos de média, com nível de significância de 0,000.

Tabela 6

Teste de diferença de médias entre tipos de candidatos e partido

\begin{tabular}{|c|c|c|c|c|}
\hline Partido & $\begin{array}{l}\text { (I) tipo de } \\
\text { candidato }\end{array}$ & (J) tipo de candidato & $\begin{array}{l}\text { Diferença } \\
\text { média (I-J) }\end{array}$ & Sig. \\
\hline \multirow[t]{2}{*}{ PDT } & \multirow{2}{*}{ Sem mandato } & $\begin{array}{l}\text { Ocupante de outro cargo } \\
\text { eletivo }\end{array}$ & $\cdot 10,286^{*}$ & 0,002 \\
\hline & & Candidato à reeleição & $-12,034^{*}$ & 0,000 \\
\hline PPS & Sem mandato & $\begin{array}{l}\text { Ocupante de outro cargo } \\
\text { eletivo }\end{array}$ & $-4,353^{*}$ & 0,001 \\
\hline \multirow{3}{*}{ PSDB } & \multirow{3}{*}{ Sem mandato } & $\begin{array}{l}\text { Ocupante de outro cargo } \\
\text { eletivo }\end{array}$ & $-11,194^{*}$ & 0,011 \\
\hline & & Candidato à reeleição & $-10,587^{*}$ & 0,002 \\
\hline & & $\begin{array}{l}\text { Ocupante de cargo não- } \\
\text { eletivo }\end{array}$ & $-17,123^{*}$ & 0,000 \\
\hline
\end{tabular}

As análises dos testes indicam que, no resultado agregado do HGPE, os partidos políticos tenderam a distribuir o espaço no horário eleitoral de forma a favorecer candidatos à reeleição e ocupantes de outro cargo eletivo: esse dado fica mais evidenciado nos casos do PDT e do PSDB, enquanto que, no agregado, o PT tendeu a destinar menos tempo proporcionalmente aos seus candidatos sem 
mandato. Resta verificar, agora, o comportamento de cada tipo de candidatura ao longo do tempo de HGPE no caso das distribuições entre homens e mulheres.

Os Gráficos 2a a 2d mostram a tendência da reta ao longo do tempo em relação ao total de segundos ocupados pelos candidatos de cada grupo. Além disso, traz as principais estatísticas representativas do comportamento dos tipos ao longo do tempo. Como se observa, os candidatos sem mandato (Gráfico 2c) são os únicos em que a curva é decrescente no período e tem o b1 negativo (-6,490E-5), com $F=1,853$. É o segundo comportamento mais consistente ao longo do tempo. No grupo dos ocupantes de cargo não eletivo (Gráfico 2b), o $F$ é um pouco menor $(0,878)$, mas, com tendência crescente e b1 $=1,130 E 5$. Isso significa que apesar de fraca relação, é mais provável encontrar um integrante desse grupo no final do período, do que no começo no horário eleitoral.

\section{Gráfico 2}

Tempo total no HGPE por tipo de candidato no período

$2 a$

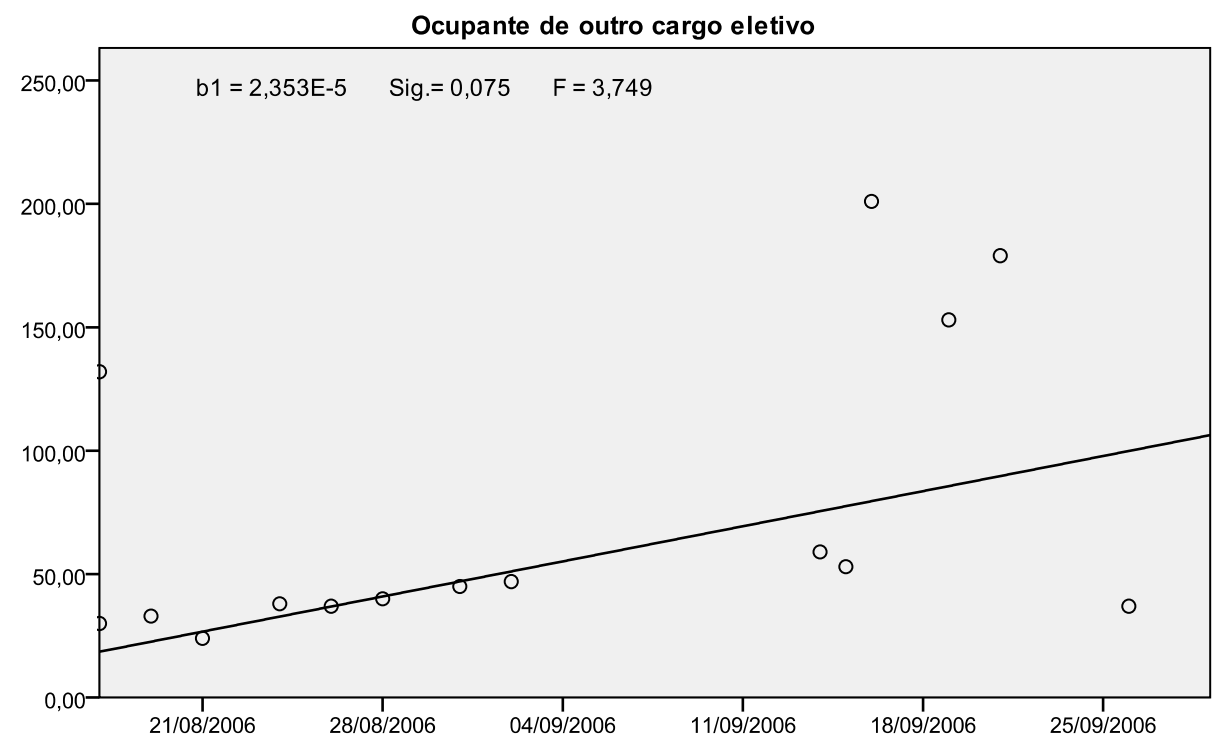


2b

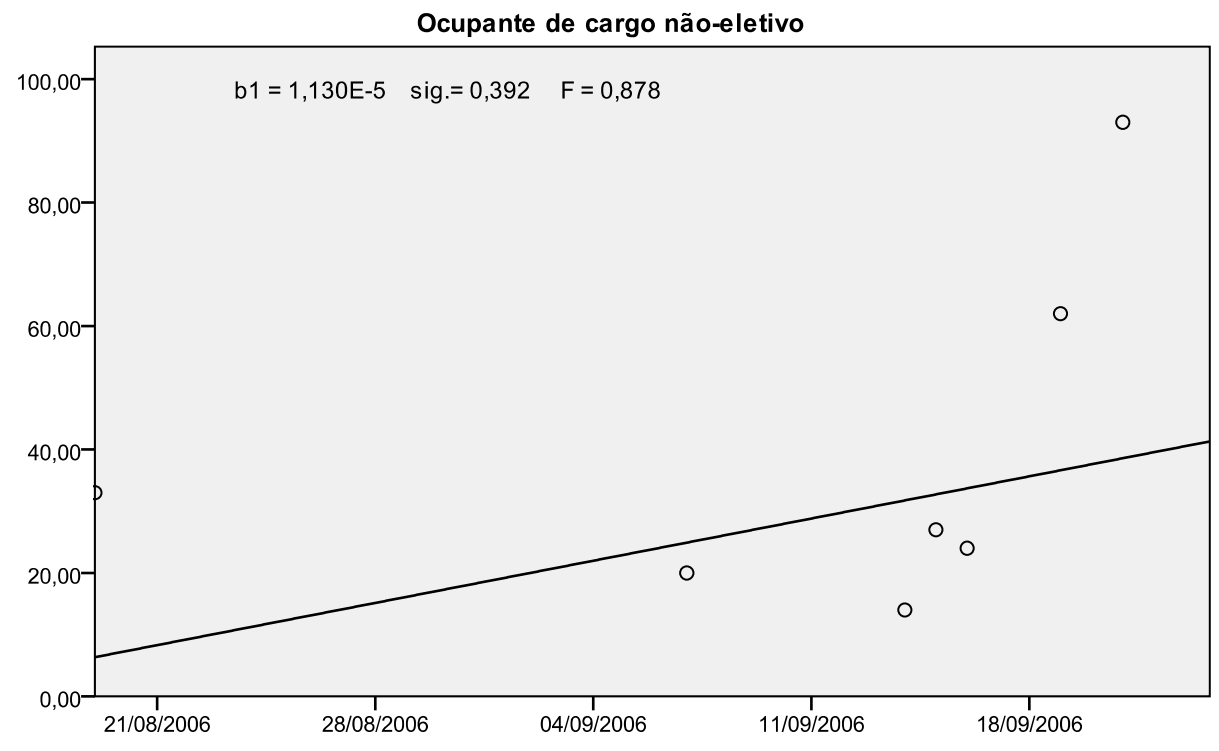

2c

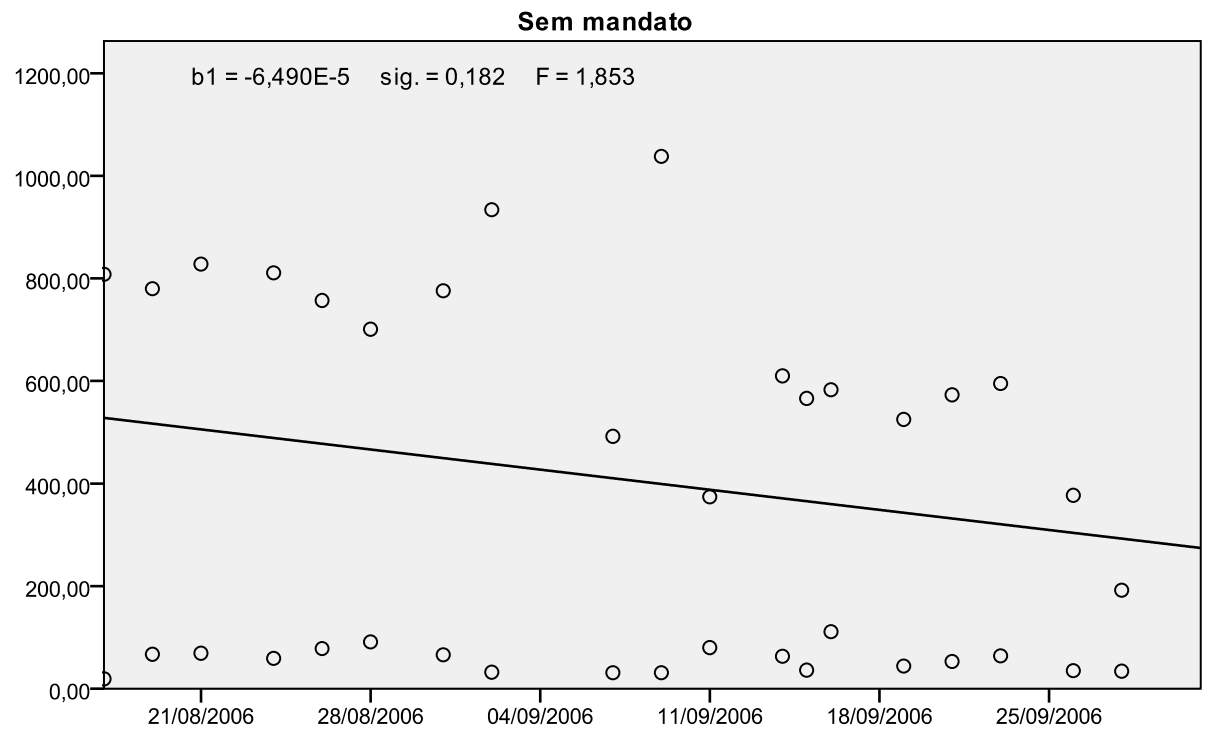




\section{2d}

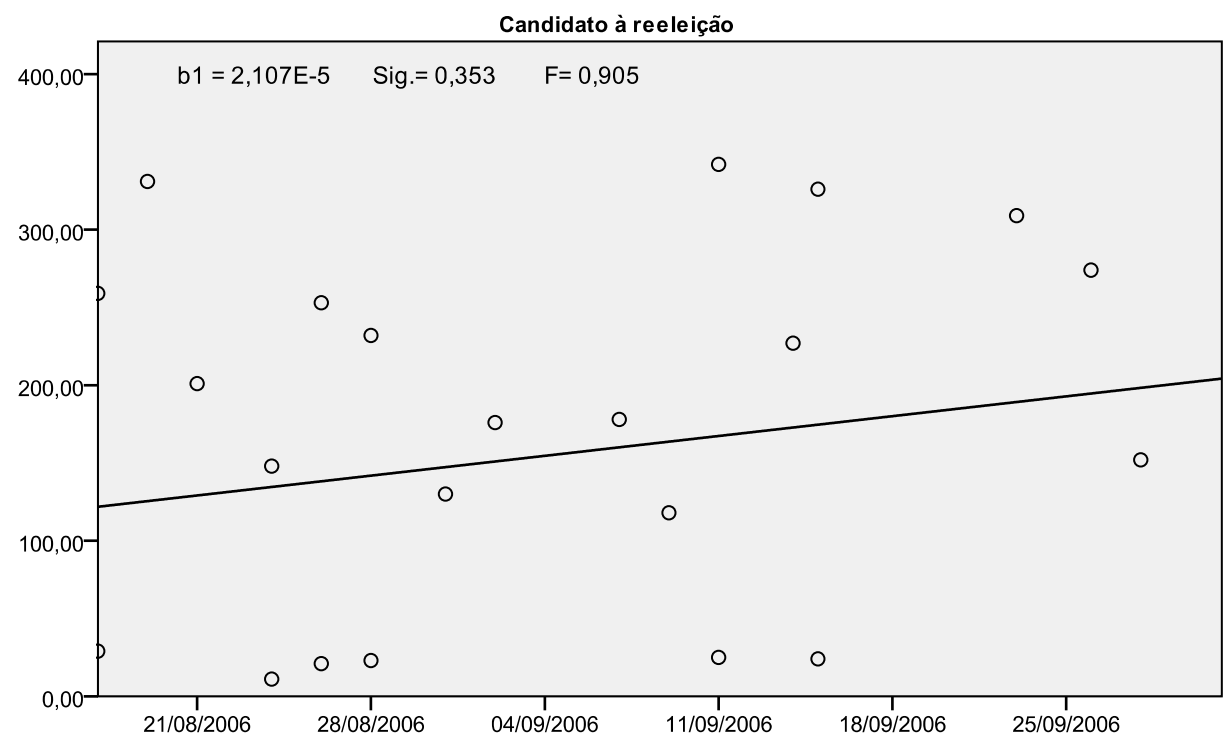

A relação mais consistente ao longo do tempo é com o grupo de ocupantes de outros cargos eletivos (Gráfico 2a). Além de ser positiva, a reta apresenta um $F$ de 3,749 e um b1=2,353E-5. Ao contrário do que se poderia imaginar, os candidatos à reeleição não são os mais beneficiados ao longo do tempo, ainda que a reta seja positiva, a estatística $F$ é mais baixa que a do grupo anterior, de 0,905, e o b1 fica em 2,107E-5(Gráfico 2d). Esse último valor é um indicativo de quanto aumentam as chances de encontrar, em um sorteio aleatório, um segundo para candidato à reeleição com o passar do tempo.

Além da distribuição ao longo do tempo, falta verificar outra característica qualitativa do HGPE que é a presença ou não de falas próprias nos segmentos dos candidatos. Aqui, pretende-se verificar se concorrentes sem mandato tendem a ter espaços menos qualificados - sem fala - quando comparados aos demais tipos de candidatos. A Tabela 7 mostra a relação entre as duas variáveis, indicando uma diferença quase constantemente em queda dos segmentos sem fala, conforme se afasta da categoria "sem mandato". No total, 33,5\% dos segmentos de candidatos sem mandato foram sem fala, sendo que para os candidatos à reeleição esse percentual cai para $14,1 \%$. Nesse caso, o teste q-quadrado para diferença de médias mostra-se altamente significativo (sig=0,000) e com um coeficiente de 28,232, comprovando que os concorrentes sem mandato tendem a aparecer "mudos" no HGPE, mais vezes que os integrantes das demais categorias. 
CERVI, E. U. O uso do HPGE como recurso partidário em eleições proporcionais...

Tabela 7

Relação entre Segmento com fala e Tipo de Candidato

\begin{tabular}{|c|c|c|c|c|}
\hline \multirow{3}{*}{ Tipo de Candidato } & \multicolumn{4}{|c|}{ Candidato com fala } \\
\hline & \multicolumn{2}{|c|}{ Não } & \multicolumn{2}{|c|}{ Sim } \\
\hline & $\mathbf{N}$ & $\%$ & $\mathbf{N}$ & $\%$ \\
\hline Sem mandato & 321 & 33,5 & 638 & 66,5 \\
\hline Ocupante de cargo não-eletivo & 2 & 16,7 & 10 & 83,3 \\
\hline $\begin{array}{l}\text { Ocupante de outro cargo } \\
\text { eletivo }\end{array}$ & 11 & 20,8 & 42 & 79,2 \\
\hline Candidato à reeleição & 23 & 14,1 & 140 & 85,9 \\
\hline Total & 357 & 30,0 & 830 & 70,0 \\
\hline
\end{tabular}

$p=28,232(0,000)$

Os dados discutidos até aqui indicam que, de maneira geral, os partidos tenderam a distribuir desigualmente o tempo de HGPE entre homens e mulheres, e entre candidatos sem mandato e outros ocupantes de algum cargo público. A diferença está em que, no caso das mulheres, apesar de serem prejudicadas em termos quantitativos, elas "ganham" espaço ao final do horário eleitoral, quando aumenta a audiência dos programas, e não se apresentam em segmentos sem fala em número maior que os homens. No caso dos candidatos sem mandato, são prejudicados tanto em termos quantitativos quanto em qualitativos no HGPE, aparecem proporcionalmente em menos segmentos, com um número menor de segundos e as aparições tendem a decair no final do período. Além disso, eles estão mais presentes em segmentos "sem fala", do que os demais tipos de concorrentes.

No entanto, não é possível, até aqui, estabelecer se o tratamento dispensado a uma das variáveis analisadas depende da relação dela com o partido político, ou se é efeito indireto da relação com a outra variável. Por exemplo, pode-se imaginar que, em função do fato de os partidos políticos terem menos mulheres eleitas ou ocupantes de cargos nomeados disputando a eleição, o tratamento desigual dado a elas seja conseqüência da falta de equidade nos tipos de candidaturas, e não devido à desigualdade de gênero. Em outras palavras, é possível pensar que a relação mais forte no tratamento estratégico dispensado pelos partidos políticos seja associada ao tipo de candidato, favorecendo os que já ocupam algum cargo político, e que as mulheres são menos favorecidas porque ainda são minoritárias nesses cargos. Para testar essas hipóteses, a Tabela 8 apresenta os resultados de uma regressão linear em que se busca verificar se sexo e tipo de candidato têm impacto conjunto sobre a distribuição do tempo no horário eleitoral. Dela constam, como variáveis independentes, o sexo e o tipo de candidato e, como variável dependente, o tempo em segundos de cada segmento. Assim, pretende-se verificar. 
OPINIÃO PÚBLICA, Campinas, vol. 17, no 1, Junho, 2011 , p.106-136

Tabela 8

Resultados do teste de regressão para tempo do segmento por sexo e tipo de candidato

\begin{tabular}{|l|r|r|r|l|}
\hline \multicolumn{1}{|c|}{ Modelo } & Beta não-padronizado & $\begin{array}{c}\text { Beta } \\
\text { padronizado }\end{array}$ & t & Sig. \\
\hline Sexo do candidato & $-1,183$ & $-0,026$ & $-0,950$ & 0,342 \\
\hline Tipo de candidato & 3,190 & 0,290 & 10,413 & 0,000 \\
\hline Variável Dependente: tempo em segundos \\
Coeficiente de correlação do modelo: $r=0,293(0,000)$ \\
\hline
\end{tabular}

Os dados gerais resultantes do modelo são significativos, com sig=0,000 e coeficiente de correlação de $29,3 \%$. No entanto, os resultados do teste de impacto conjunto das variáveis explicativas sobre a distribuição de tempo mostram que não há relação significativa entre sexo do candidato e duração do segmento, com sig=0,342 e estatística $t=-0,950$. Para a variável "tipo de candidato", a relação é estatisticamente significativa, onde $t=10,431$ e o nível de significância bem abaixo do limite crítico, em 0,000. O beta não-padronizada para a variável tipo de candidato é de 3,190, ou seja, conforme muda o tipo de candidato, de tipo sem mandato até tipo candidato à reeleição, o tamanho médio dos segmentos no horário eleitoral tende a aumentar em mais de 3 segundos.

Este último teste demonstrou que o tratamento destinado às mulheres no HGPE não se deve, necessariamente, à questão de gênero. Levando em conta todos os partidos analisados aqui, as mulheres recebem menos tempo no HGPE porque são predominantemente sem mandato e a desigualdade na distribuição do recurso partidário estudado se deve-se, antes, à predominância de candidatos à reeleição ou ocupantes de outros cargos nos maiores e melhores espaços do horário eleitoral. Porém, não se pretende com isso obter afirmações definitivas. A distribuição de poder dentro de um partido político vai além da distribuição do espaço no HGPE e entender como se dá a ocupação desse tempo é importante como ponto de partida para avaliações sobre como essa disputa se materializa no horário eleitoral.

\section{Apontamentos finais}

Os achados empíricos apresentados permitem dizer que as direções partidárias e coordenações de campanhas eleitorais utilizam o recurso "horário eleitoral" de forma estratégica.Identificou-se um padrão na forma de utilização do espaço do HGPE pelos partidos em relação aos candidatos que disputaram vagas de deputado federal pelo Estado do Paraná em 2006. Se o PDT foi o partido que cedeu menos espaço para as mulheres naquele ano, em relação ao tipo de 
candidatura, as diferenças de tratamento foram ainda mais evidentes. De maneira geral os partidos dão maior espaço e tempo mais qualificado a candidatos ocupantes de outro cargo eletivo e aos concorrentes à reeleição. Isso ocorre tanto em relação ao número de segmentos e tempo total, quanto à posição ao longo do período e ao tipo de aparição (com ou sem fala).

O tempo de televisão é destinado, preferencialmente, a candidatos que já passaram pelo teste das urnas ou que têm influência nos governos e cúpulas partidárias (no caso dos ocupantes de cargos não eletivos). Mulheres têm uma participação menor do que deveriam na divisão do horário eleitoral; no entanto, mulheres com mandato ou ocupantes de cargo por indicação tendem a ter espaços mais qualificados que homens sem mandato. Os maiores prejudicados são os candidatos novos, sem mandato, preteridos em todos os sentidos. Os dados para a campanha para deputado federal do Paraná em 2006 permitem apontar que a forma como o HGPE é usado pelos partidos reforça uma tendência de concentração de recursos em determinado tipo de candidato, reforçando o padrão já existente, ao mesmo tempo em que diminui o potencial de renovação de fato das bancadas partidárias.

Como já se afirmou no início do trabalho, o objetivo aqui não foi apresentar resultados a respeito do instrumento metodológico proposto, embora os resultados apontem para uma distribuição desigual do recurso HGPE para candidatos às disputas proporcionais em todos os partidos. Também há apontamentos iniciais indicando que concorrentes que não ocupam cargos públicos e mulheres tendem a ocupar espaços menos nobres do horário eleitoral. De qualquer maneira, esses dados preliminares precisam ter sua validade testada a partir do debate sobre o instrumento de pesquisa.

Como os estudos de HGPE no Brasil iniciaram a partir das eleições majoritárias, no final dos anos 1980 (ALBUQUERQUE, 1996), a pesquisa sobre esse tipo de horário eleitoral desenvolveu-se mais rapidamente do que as análises sobre as disputas proporcionais. Vale ressaltar, também, que essa não é a primeira tentativa de sistematização do papel do HGPE proporcional das disputas eleitorais brasileiras. Albuquerque et al (2007) já estudaram a relação entre o tipo de apresentação de candidatos a vereador no Rio de Janeiro em 2004 e a distribuição dos votos obtidos nas diferentes regiões da cidade, mas não com o objetivo de descrever a gramática do programa, relacionando-a com a distribuição de recursos partidários aos candidatos, como foi realizado neste trabalho.

O objetivo do presente estudo foi discutir formas de quantificar dois conjuntos de características do horário eleitoral proporcional. Inicialmente, medir a quantidade e a qualidade de tempo distribuído pelos partidos e coligações aos candidatos, relacionando as características dos concorrentes, tais como tipo de candidato, sexo e tipo de orador. Segundo, discutir como os candidatos usam esse 
espaço recebido dos partidos para moldar uma imagem pública a partir dos elementos mencionados, do tipo de apelo ao voto, da temática tratada e do uso de símbolos e indumentárias atípicas. Portanto, o objetivo foi apresentar uma forma, entre muitas outras possíveis, de discutir o HGPE a partir dele mesmo, tentando entender as relações entre fenômenos políticos e comunicacionais presentes nas manifestações constrangidas pelas regras do horário eleitoral.

Não se acredita possível transpor qualquer resultado da análise gramatical ou semântica do HGPE tendo impacto direto no desempenho eleitoral dos concorrentes. O que se busca é aprofundar os estudos sobre política e comunicação em disputas proporcionais, considerando o horário eleitoral como um instrumento de distribuição de recursos políticos partidários aos candidatos, e destes aos eleitores/telespectadores, sem uma relação de causa-efeito direta entre as intenções e escolhas dos candidatos no HGPE e as decisões dos eleitores.

\section{Referências Bibliográficas}

ALBUQUERQUE, A. A Gramática do Horário Gratuito de Propaganda Eleitoral: Observações Preliminares. In: NETO, A. F. e PINTO, M. J. (Orgs.). O indivíduo e as mídias. Rio de Janeiro: Diadorim, 1996.

Política Partidária e Política Midiática: Substituição ou Coexistência? Contemporânea, v. 3, n. 1, p.9-37, 2005.

- Notas para uma agenda de pesquisa sobre a propaganda política na televisão no Brasil. Revista ECO-Pós, v. 12, n.3, p.4-10, 2009.

AlBuQUerQue, A; STEIBEL, F. B; CARNEIRO, C. M. Z. A Outra Face do Horário Gratuito: Partidos Políticos e Eleições Proporcionais na Televisão, 2007.

BAUER, M. W. \& GASKELL, G. Pesquisa Qualitativa Com Texto, Imagem e Som: um manual prático. Petrópolis: Editora Vozes, 2003.

CAIN, B., FEREJOHN, J. e FIORINA, M. The Personal Vote: Constituency Service and Electoral Independence. Cambridge: Harvard University Press, 1987. 
CERVI, E. U. O uso do HPGE como recurso partidário em eleições proporcionais...

CERVI, E. U. Instituições democráticas e financiamento de campanhas no Brasil: análises das contribuições de pessoas físicas, jurídicas e partidos políticos às eleições de 2008 e o financiamento público exclusivo de campanha. Paper apresentado no $33^{\circ}$ encontro anual da Anpocs, Caxambu, 2009.

CONDE, M. R. B e ROMÁN J. A. Investigar en comunicación: guia práctica de métodos y técnicas de investigación social en comunicación. Madrid: Mc Graw Hill, 2005.

DIAS, M. R. Projeção da Imagem Partidária nas Estratégias de Campanha na Televisão: Uma Análise do HGPE 2002, Revista de Ciências Sociais, Rio de Janeiro, Vol. 48, n. 1, p. 149-187, 2005.

GIBSON, R. e RÖMMELE, A. "Changing Campaing Communications: A PartyCentered Theory of Professionalized Campaigning". Harvard International Journal of Press Politics, vol. 6, n. 4, p 31- 43, 2001.

LAWSON, K. e MERKL, P. When Parties Fail: Emerging Alternative Organizations. Princeton: Princeton University Press, 1988.

MANCINI, P. e SWANSON, D. L. "Politics, Media, and Modern Democracy: Introduction", In: SWANSON, D. L. e MANCINI, P. Politics, Media and Modern Democracy: An International Study of Innovations in Electoral Campaigning and their Consequences. Westport/London: Praeger, 1996.

MAINWARING, S. "Brazil: Weak Parties, Feckless Democracy", In: MAINWARING, S. e SCULLY, T. R. (eds.), Building Democratic Institutions: Party Systems in Latin America. Stanford: Stanford University Press, 1995.

MAHONEY, J. \& GOERTZ, G. A Tale of Two Cultures: Contrasting Quantitative and Qualitative Research. Political Analysis Review, n. 14, p. 227 a 249, 2006.

NEVES, D. S. A primeira reeleição de Curitiba - Campanha de Cassio Taniguchi no Horário Gratuito de Propaganda Eleitoral (HGPE) nas eleições municipais de Curitiba em 2000 In: MIGUEL, L. (Org.) Dossiê Mídia e Política. Revista de Sociologia e Política, Curitiba, n. 22, p. 7-12, 2004.

MORETTIN, P. A. \& TOLOI, C. M. Análise de Séries Temporais. São Paulo: Editora Edgard Blücher, 2004.

NEGRINE, R. M. e LILLEKER, D. G. "The Professionalization of Political Communication: Continuities and Change in Media Practices". European Journal of Political Communication, v. 17, p.305-323, n. 3, 2002.

OLIVEIRA, C. B. Horário Gratuito Político Eleitoral - HGPE: O Eleitor e a Cidadania Política. Porto Alegre, 2008. 
RAGIN, C. C. Constructing Social Research: the unit and diversity of method. Thousand Oaks: Pine Forge Press, 1994.

SAMUELS, D. Determinantes do Voto Partidário em Sistemas Eleitorais Centrados no Candidato: Evidências sobre o Brasil. Dados, v. 40, n. 3, p. 493 a 533, 1997.

SCHMIDT,M. When Parties Matter: A review of the Possibilities and Limits of Partisan Influence on Public Policy. European Journal of Political Research, v. 30, n. 2, p. 155-183, 1996.

WATtenBERG, M. P. The Rise of Candidate-Centered Politics. Cambridge London: Harvard University Press, 1991.

Emerson Urizzi Cervi - ecervi7@gmail.com

Recebido para publicação em dezembro de 2010. Aprovado para publicação em março de 2011. 